\title{
Fiscal Sustainability, the Labor Market, and Growth in Saudi Arabia
}

\author{
Ishac Diwan
}

\section{INTRODUCTION}

The drop in oil prices since mid-2014 has opened up a twin-deficit in the state budget and the balance of payment of Saudi Arabia. The specificities of the current shock are its extraordinary size ( 50 percent fall in oil prices), the fact that it comes on the heels of a long period of high prices (2000-2014), and the high probability that it will be permanent rather than transitory. As a result, the non-oil economy will have to be taxed to balance the books. But the implied tax rates are very high because of the narrowness of the non-oil economy and its dependence on the oil economy. Thus, unless the tax base grows over time, deep cuts in domestic consumption will have to be envisaged. But while the current shock brings more immediacy to the question of how to adjust to lower oil revenue, with a rising population, and oil revenue expected to fall over time as interest in climate change increases, the rentier mode of development followed by Saudi Arabia was clearly unsustainable to start with.

I. Diwan $(\bowtie)$

Ecole Normale Supérieure, Paris Sciences et Lettres, Paris, France

(C) The Author(s) 2021

G. Luciani, T. Moerenhout (eds.), When Can Oil Economies Be

Deemed Sustainable?, The Political Economy of the Middle East, https://doi.org/10.1007/978-981-15-5728-6_3 
On this diagnostic, most analysts agree. But what should replace the current economic model? Here, pundits are deeply divided: some believe that the inadequacies of the current economic model will necessarily lead, sooner or later, to a doomsday scenario of instability and pauperization; others advocate a move from the current economy still dominated by hydrocarbons to a modern and diversified knowledge-based economy, OECD-style. What seems to be missing in the current discourse on Saudi Arabia is a more reasonable vision for the future, one that not only resolves the problem of non-sustainability of the current path but that, at the same time, would also be desirable and feasible.

This confusion in the economic discourse about the kingdom has its source in the unusual structure of its labor market. The steep dualism between expatriates and national workers is unique among large countries. The main problem with the current economic system is that under it, nationals are simply not employable in large numbers in the private sector. In this chapter, I argue that the main challenge to building a better future is to find ways to employ them productively. Doing so would greatly boost growth: indeed it may be the only source of growth that is currently readily available. It would also save on the foreign exchange now being remitted by expatriates abroad, reducing the need to produce tradables besides oil. But because the current division of labor between nationals and expats is deeply inscribed in the current social contract, the Kingdom will have difficulty in balancing the interests of businesses and society at large.

This chapter explores these issues in turn-the size of the current shock and the magnitude of the fiscal challenge, the need to find a realistic and effective new growth model, the challenge of increasing the national labor force participation, the implied policy challenges at the macro and corporate levels and, finally, the type of political economy constraints that will be encountered. Its value added is not so much with highlighting each of these issues, which have been somewhat explored in the past, as much as it is with its claim that addressing the current challenge requires a strategy that "normalizes" the Saudi economy. The discussion also highlights the main areas of economic and social behavior that require a much better understanding for effective policies to be devised in the years ahead. 


\section{Sizing-Up the Macro SHOck}

The first specificity of Saudi Arabia (KSA thereafter) today is the extraordinary size of the macro shock that has hit its economy. According to the $\operatorname{IMF}(2017,2018)$, oil exports dropped by half, from around $\$ 300$ billion/year during 2012-2014, to \$140-160 billion/year during 2015-2018. Oil revenues that accrued to the state budget represented close to 90 percent of government revenues in 2014, and they have dropped from SAR 913 billion in 2014, to an estimated SAR 454 billion in 2017-2018.

By most accounts, the current depressed level of oil prices, which dropped from about $\$ 100 /$ barrel during the decade that ended in 2010, to about $\$ 50$ afterwards, is unlikely to fully recover in the medium term, given demand and supply projections. This means that there is a good chance that the old level of prices will never be recovered. Although this assertion can be debated, we will consider this hypothesis as our starting point. The implication is that the fiscal deficit resulting from this massive negative shock cannot be financed forever, and that there is therefore a need, sooner or later, to adjust the budget to the new level of oil prices.

The burden of the adjustment is made harder by the fact that by 2014, a year with record oil revenues, the budget was already running a (small) deficit. This is unlike the situation of the previous oil shock of the 1990s, when the kingdom was running a large surplus, and when the needed expenditure cutback was therefore more limited. It is also unlike the situations of most other GCC countries today (except Bahrain and Oman), which were running large surpluses in 2014, and where the negative shock only reduced this surplus, or turned it into a small deficit.

The size of the shock can be appreciated in several ways. In 2015-2016, the fiscal deficit was about SAR 400 billion/year (or 16 percent GDP), in spite of the initiation of some budget cutting measures. By 2017, the deficit was cut by nearly half, to about SAR 240 billion ( 9.3 percent GDP), largely through deep cuts in public investment, which were running at a record high level to start with. In addition, a long-standing taboo was broken with the introduction of several new taxes (excise, VAT), and the initiation of increases in the domestic prices of energy and water, sectors that have been heavily subsidized to date. By 2017, public investment has fallen to a third of its 2014 level, to 7 percent of GDP, and non-oil revenues rose from 4.6 to 7.5 percent of GDP (see Table 3.1). So, by the end of 2017, what has been achieved is already a large fiscal adjustment by 
Table 3.1 Central Government Budget 2014-2022 (SAR, billions)

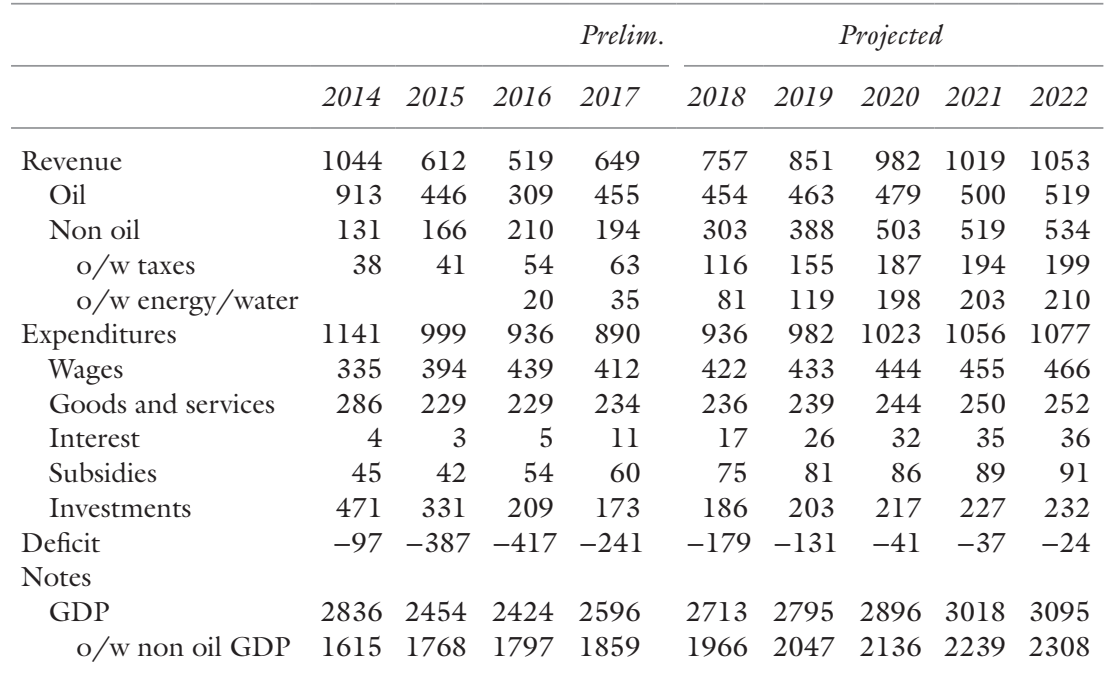

Source: IMF article IV (2017)

global standards. But the adjustment so far has been relatively easy, as there is not more room left for reductions in the investment budget.

In spite of these considerable efforts, the fiscal deficit remained sizable at the end of 2017, as there was still about SAR 241 billion of excess of expenditure over revenues (9.3 percent GDP). Since the deficit has to be financed from the non-oil part of the economy, one gets a better sense of its magnitude by expressing it as a share of non-oil GDP. By this measure, it stood at 13 percent of non-oil GDP at the end of 2017, a large figure (down from 22 percent of non-oil GDP in 2015 and 2016). At the same time, the need to finance the deficit during the past 4 years has led public debt to rise from 1.6 to 19 percent GDP already, and external reserves to be reduced from $\$ 724$ to $\$ 473$ billion between 2014 and 2017 .

The challenge ahead will be more difficult, as the type of expenditure left on the budget are more difficult to compress. Wages and compensation of public servants now approach 50 percent of expenditure, and interest payments have started to rise. Moreover, as new taxes and new tariffs start hurting poorer households, the need for some compensation will arise. The government is finalizing a cash transfer program (called the citizen account), which should start disbursing during 2018. 
The government is thus left with only two choices in the short term: to increase revenues and to finance (the remaining) deficit. ${ }^{1}$ The government has taken an aggressive stance at deficit reduction, signaling that it intends to increase taxes and cost-recovery rapidly. Whether this will happen, however, remains to be seen. To get a sense of the magnitude of the needed adjustment, government plans foresee to eliminate the deficit by 2020 . To achieve this ambitious goal, tax revenues are projected to rise to SAR 200 billion by 2022 (VAT initially at 5 percent and rising afterwards, excise on tobacco and drinks, and higher expat fees), from a base of SAR 38 billion in 2014, and water and energy cost recovery are projected to rise by SAR 210 billion. In addition, non-tax revenues are expected to also rise due to an ambitious program of privatizations. This financing effort represents, therefore, about SAR 400 billion of additional revenues that will have to be paid by national households, corporations, and expatriate workers.

The important question is whether these expectations are realistic. The risk is that the planned increase in revenues meets serious social resistance and is rolled-back, and that the gap will continue to be filled up with debt. By some estimates, the kingdom can borrow abroad and sell assets to theoretically finance at least 10 years of deficits at the current level, before going bankrupt. This allows it to kick the can down the road rather than find more sustainable solutions, as has often happened to regimes built on oil (Karl 1997).

\section{The Stabilization Challenge}

To gage of the realism of the kingdom's fiscal objectives, it is important (but difficult) to get a sense of the incidence of the planned fiscal effort on the various parts of the population.

Expats do create a buffer for the economy but are unlikely to be part of the tax base. The predominance of expats in the construction sector (Fig. 3.1) meant that, unlike other countries, the recent and ongoing closing-down of major infrastructure projects has not created large unemployment among nationals, as instead, the expat labor force has shrunk (Mahroum 2016). One presumes however that expats are being paid their reservation wage, and while they can be fired at will, it is not possible to

\footnotetext{
${ }^{1}$ Ending the war in Yemen would also lead to savings - but these costs are not detailed in the government budget as presented in IMF and other public documents.
} 


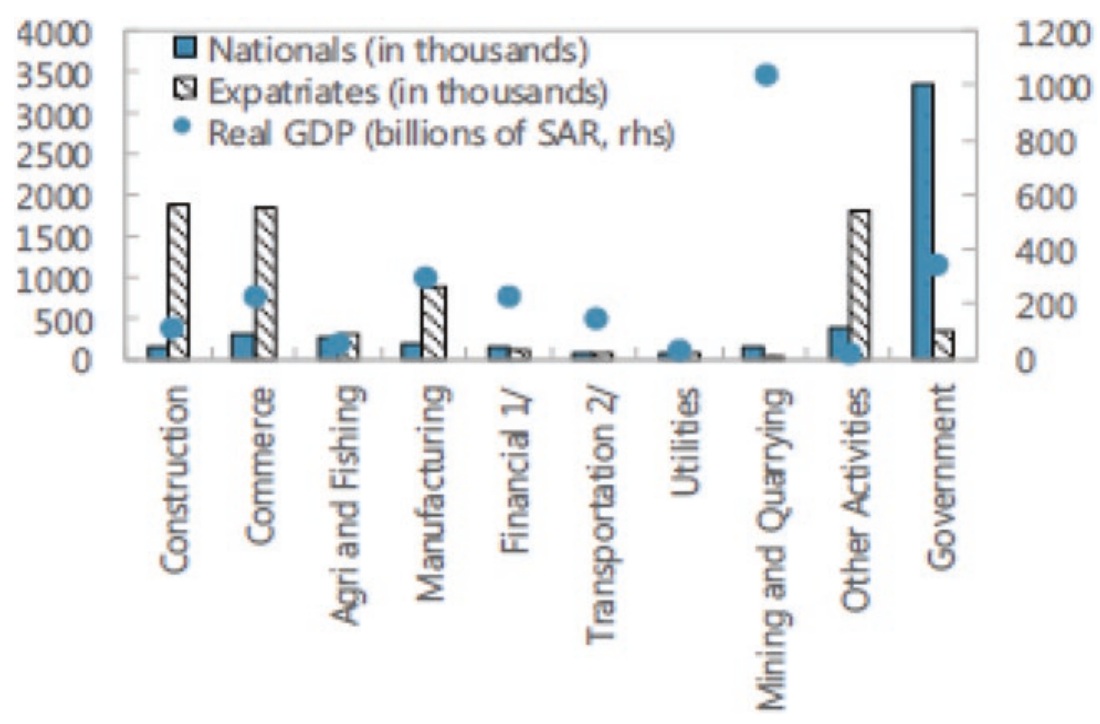

Fig. 3.1 Employment and Real GDP by sector (2016). (Source: IMF Article IV (2017))

compress their net incomes by much and keep them employed. Thus, while several fees are levied on them already (work permit, residence permit, training charges), and while these fees are expected to rise more in the future (by a total 2.2 percent of GDP by 2022 , according to IMF projections), one expects that such additional costs will have to be borne by their employers rather than through a compression of their net income. ${ }^{2}$ Some more research on this issue, taking advantage of recent increases in these fees, will be useful to understand this central set of issues better.

The burden of taxation and cost recovery will, therefore, have to fall largely on Saudi households and firms. Concerning firms, there is little knowledge of how large their profits are-there is actually no such data, since corporate revenues are not taxed. Thus, it is not clear to what extent they would be willing to absorb the new taxes and higher input prices through reductions in their profits, as opposed to choosing to either close down their operations (especially for those in the traded sector), or to pass on the increased burden to consumers (especially for those in

${ }^{2}$ The same logic applies to the VAT and rise in utility tariffs that apply to them. 
non-tradables). There are indications that, in the aggregate, profitability is on the high side: the non-oil corporate sector has been growing fast in the past decade, and its investment rates can be estimated roughly from the national account to be about 25 percent of non-oil GDP, a pretty high figure which suggests overall high levels of profitability. Large firms traded on the stock exchange, and listed in the Orbis database, tend to report large profits. ${ }^{3}$ Moreover, the private sector as a whole has relatively high access to credit, as total credit to the private sector is reportedly at about 90 percent of non-oil GDP, again, a large figure by international standards.

But it seems plausible to think that the corporate sector is highly dualistic, with large corporations benefitting from a privileged access to the credit market, and facing less competitive pressures than smaller firms (Hanieh 2016). This would imply that large firms are able to absorb more losses than SMEs. It should be noted however that state ownership in the largest firms is quite sizable-directly at about 45 percent, and overall even more, given state stakes in banks and insurance companies that own another 15 percent of these firms (Coksun et al. 2018—see Fig. 3.2). This

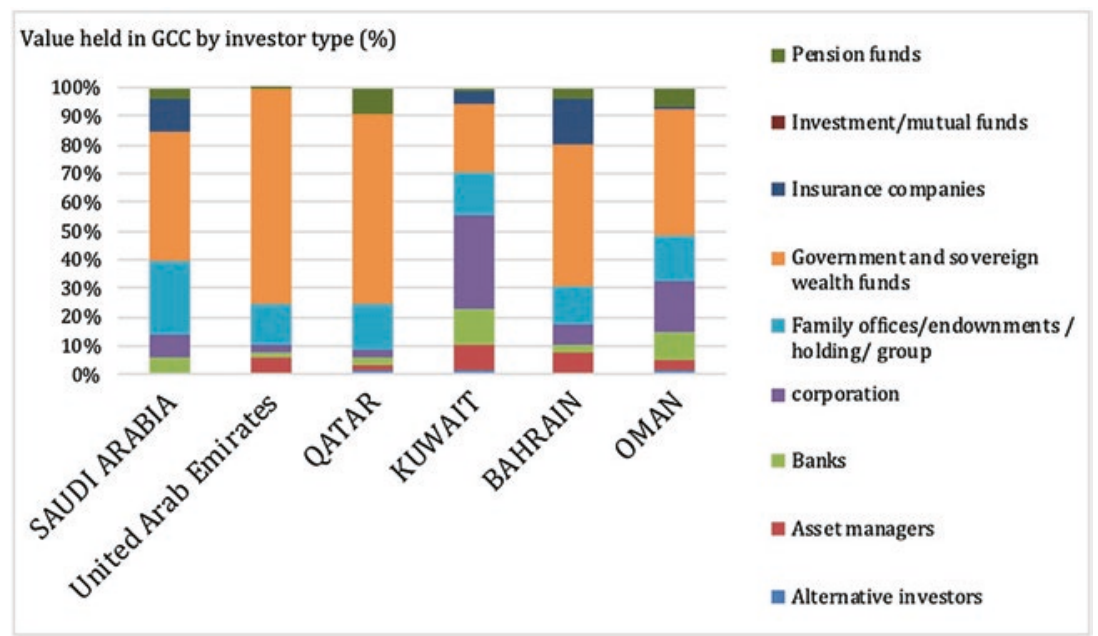

Fig. 3.2 Ownership of traded companies in the GCC. (Source: Coskun et al. 2018)

${ }^{3}$ Excluding the petrochemical companies and energy utilities, their profit rates (relative to revenues) were of the order of 17 percent in 2014, falling to 15 percent in 2016 (IMF 2017). This can be considered high by international standards. 
limits the net financial gains of passing the burden of adjustment on such firms. At the same time, there are indications that smaller firms operate in a highly competitive environment, and that they are already hurting from the deteriorating market conditions. More research is needed to understand in more detail the performance of the corporate sector and its ability to sustain more taxation, as this will help devise better policies in the years ahead.

There is a possibility of taxing wealth, such as bank accounts, and other forms of assets. There has been to date no indication that this may take place formally, although the episode of the Ritz-Carleton hotel suggests that this may take place informally, at least at the top of the corporate pyramid. There have been reports of large amounts of capital flight in recent years, which suggests that capital-holders are trying to shield their assets from potential taxation and state predation.

To get a sense of magnitude of the burden on households and corporations implied by the IMF projections, I will try below to heroically estimate a lower and upper bound aggregate tax rate. As described above, the new taxes announced are essentially a VAT and excise taxes, which will fall directly on households; higher expat fees, which indirectly affect profits and consumer prices; and increased utilities prices, which fall directly on consumers and firms, but that may end up falling more on consumers via their indirect influence on output prices.

One extreme assumption one can make is that all of the burden will fall on Saudi households. If that were the case, the burden would be unbearable. To get a feel of magnitudes, 70 percent of working Saudis work for government, and their total compensation in 2017 was SAR 412 billion (Table 3.1). Even if one accounts generously for income earned by Saudis in the private sector (which is unlikely to be more than a third of this amount), and from non-labor sources (such as return on savings and other assets), it is apparent that the burden of the extra taxes and utility costs will be a large proportion of their income-possibly more than half?

A lower bound would consider a larger tax base that includes corporate profits and self-employment earnings. Non-oil GDP stood at SAR 1.8 trillion in 2017. One can estimate based on ministry of labor data that total expats income is about SAR 600 billion. Taking this out leaves about SAR 1.2 trillion of non-oil national income, which, together with the public sector wage bill, adds to a total tax base of about SAR 1.6 trillion. With this larger tax base, a lower bound estimate of the average tax burden would stand at about 25 percent, a lower, but still quite a large burden. 
We can conclude that the current financing goals are not realistic. For the burden of adjustment to become bearable in the medium term, nonoil GDP needs to rise in ways that boosts the tax base. More realistically then, a strategy to eliminate fiscal deficits that can work would be more gradual, and it would rely centrally on pro-growth reforms that increase the size of the tax base over time. As long as this does not happen, public debt is likely to continue to rise. There are moreover financial limits to the extent of gradualism, since both slow fiscal adjustment and growthinducing reforms require financing. There is thus a central trade-off: if adjustment is too fast, it would be resisted socially; but if it is too slow, it would consume much of the fiscal space, leaving little financing resources available to invest sufficiently in new sources of growth.

\section{What Growth Strategy?}

The government has announced ambitious plans to boost private sector growth, including improvements in the business climate, in trade logistics, and in the application of the rule of law. In the IMF scenario-which is reportedly more conservative than government expectations-these reforms are expected to increase non-oil GDP growth by 3 points by 2020 , for a total of 3.5 percent growth per year. This seems quite optimistic, given the large weight of government spending in fostering growth in the past; and it says little about the potential for medium term growth, because the growth model itself remains fuzzy and poorly defined. The question of interest is, therefore, what growth model can deliver a larger tax base? From a longer-term perspective, oil rents are not sufficient anymore to finance anything close to the current consumption levels of the population, and this can only get worse over time in the absence of a new source of growth. With its current population of 23 million, and oil revenues of only $\$ 6000$ per capita, Saudi Arabia has clearly outgrown its current model. A new growth model would also allow consumption to grow again after a necessary adjustment, and a credible model could even justify a temporary smoothing of consumption until growth picks up again, fueled by a new economic reactor.

In the short term, growth will be made harder by the headwinds created by fiscal stabilization itself. Cuts in government expenditure create a drag on non-oil GDP growth, whose size depends on the size of the "fiscal multiplier". The multiplier depends on how much of government spending ends up as imports and remittances-the larger these, the smaller the 
"multiplier". It has been estimated, based on historical data that the shortterm multiplier is quite low at about 0.5 (Espinoza et al. 2013). This means that large leakages reduce the growth impact of government expenditures. Still, one would expect a cumulative fall in the growth of non-oil GDP on account of a stabilization effort of about 10 percent of GDP to be about 5 percent points. Already, non-oil GDP growth, which was growing fast before the 2014 shock, has halted to about zero. The stabilization drag is expected to continue to operate for several years as firms adjust their level of operation to lower levels of government spending.

But what will drive economic growth in the medium and long terms? There are several reasons to believe that the main source of growth available in the medium term is the increase in the labor force participation of Saudi nationals.

From a tax collection perspective, GDP growth per se does not tell us much about the economy's ability to absorb increased revenue collection, which depends not just on growth rates, but on the type of growth. A path of labor intensive growth leveraged on expat labor can allow for larger taxation of corporate profits, but if it does not manage to increase employment among Saudis, it would require more social spending to preserve social peace, and thus, would not be conducive to correcting the macroimbalances. On the other hand, growth based on the expansion of Saudi labor would lead to a broader tax base over time.

More broadly, only 40 percent of working-age nationals participate in the labor force (but only 35 percent work, as the rest are unemployed). This compares to labor participation rates of about 60 percent in the OECD. Low Saudi participation rates are largely due to very low participation by women ( 19 percent), but men's participation ( 55 percent) is not high by international standards either. Huge gains could be made if they were instead encouraged to do so, because Saudi nationals are both grossly underemployed and increasingly well educated, thus increasing the opportunity cost of low participation. To give a sense of the potential gains if national labor was employed more effectively, a simple projection model suggests that, with participation rates growing from 40 to 60 percent of the working-age population and unemployment dropping to its natural rate, non-oil national income would more than double if the additional workers join the non-oil sector at current productivity levels. Improvements in labor productivity would add to this growth rate further. Altogether, it can be estimated that this addition to national wealth is comparable in magnitude to the kingdom's current oil wealth. 
The extent of economic gain that can be obtained by fixing other inefficiencies, or by removing other constraints to growth, pales in comparison. The total cost of energy subsidies is about 7 percent GDP-there is certainly much over-consumption given low prices, but the extent by which the economic pie can actually be increased on this front is limited. Importing technology to increase productivity, the classical catch-up development policy, is desirable, but the reason for the relatively low labor productivity in the past has not been the lack of openness of the Saudi market to outside influences, but rather, the incentive of firms to use labor-intensive technologies, which is itself connected to the widespread availability of cheap (imported) labor.

This poses the question of the employability of Saudi citizens. Jobs cannot come from an expansion of the civil service. The government is no longer hiring all Saudis who are willing to work. And in the current economic environment, nationals are simply not employable in large numbers in the private sector. Already, unemployment is officially at 11.6 percent overall, 32.8 percent for women, and 29.4 for youth, and rising. Moreover, there are about 200,000 new entrants to the labor market every year.

One can envision a worst case scenario, where dwindling oil revenues continue to be shared among the nationals, cheap labor continues to be freely imported, and Saudi reservation wages only fall slowly over time as oil rents per capita decline. In such a scenario, the kingdom will turn into an increasingly impoverished welfare state, with rising unemployment and lower labor force participation. Moreover, income inequality would rise fast, as business-owners continue to enrich themselves by exploiting cheap expat labor, while the rest of the population gets poorer over time. Governance, which has relied largely on the co-optation of citizens, could become more repressive, as has happened in the countries of the region with smaller oil endowments and larger populations, such as Iraq or Algeria (Cammett et al. 2019).

Besides the no-reform slow-impoverishment scenario, an equally undesirable strategy is one that uses the existing fiscal space to finance a costly pie-in-the-sky national project that does not deliver sustainable growth. Some elements of the Vision 2030 can be read in this manner, and especially those that project Saudi Arabia to become a sort of Dubai on steroids, with Saudi youth managing a large population of migrant workers in a super-competitive knowledge economy. The challenge for such a strategy is to make middle-skill Saudi workers complementary to expat workers. Such a vision seems too ambitious at the macro level for a 
country the size of KSA. One can think at best of particular sectors, where such a production strategy can make sense, but it cannot cover the whole economy. But even then, insulating sectors with cheap foreign labor from others that employ higher skill national workers runs again in the same problem as with the current quantitative restrictions on labor use-the existence of cheap unskilled expats will reduce the incentives of firms to increase capital investment and improve efficiency and wages in the sectors selected for upgrades.

While the more pessimistic scenario is the more likely of the two, both fail to present a reasonable vision for the country's next 20 years, when oil revenues are likely to remain sizable, but not sufficient to sustain the current model of development. It must be evident to many Saudis that it is high time for the productive structure to adapt to the new realities. The country's human and real assets have changed profoundly in the past 50 years. While importing labor to build the country made sense in the past, there are now large cohorts of educated Saudis graduating and aspiring to productive employment. The situation is thus profoundly different, and it requires profoundly different economic incentives. The massive import of foreign labor was a response to an exceptional situation, unseen in these proportions in any other country at any other time. This period has now to come to an end.

To employ its youth gainfully, Saudi Arabia now needs to become a "normal" oil economy-like, for example, Norway-that exports mostly, if not only, oil, but that derives national income from the work of its own population, primarily in the service sector. In this "normal" model, Saudi workers would replace expatriates, largely in service jobs. The economy would remain dominated by a large oil sector (which includes backwardand forward-linked sub-sectors), employing specialized national workers (e.g., about 50,000 oil engineers). A large share of the Saudi labor force (say half) would remain employed in government; and many public-sector firms would continue to play an important economic role, employing specialized Saudi workers in the oil, health, academic, telecom, and finance industries.

The new jobs would largely be in high-productivity occupations in the service sector. Except in a few areas of comparative advantage, not many firms would produce globally competitive tradables; those that do so now would be unlikely to survive given that unskilled wages would rise, capital would come at a higher cost, subsidies would be cut, and taxes would be 
introduced. At best, a few tradable sectors could thrive, such as religious tourism and sectors with close linkages with petroleum-at least initially.

At the end of this transition, millions of expatriates would have returned to their home countries, having provided a vital contribution to the task of building up a modern country at record speed. The Saudi economy would become smaller, but it would employ a large share of its own population productively. At the end of the day, the 6 million expats working in private sector firms may be replaced by less than 1 million Saudi workers, employed at higher productivity and at higher wages. The private sector may shrink considerably - even as the tax base grows. The economy may end up with a lower GDP, but it would produce a larger national income. Oil would remain central, but it would have a much larger multiplier effect in terms of the domestic employment of nationals.

In sum, the main economic challenge of the transition to a normal economy is to create highly productive jobs for nationals. It is easy enough to create high-paying jobs-in the public sector, including the security forces, or by replacing migrants in labor-intensive private-sector occupations. But the first option (creating new public-sector jobs) would expand fiscal deficits unsustainably. The second option (replacing expatriate workers with nationals) can deliver high wages in the non-tradable service sector if the total number of migrant workers is reduced sharply. But unless productivity rises too, this would be reflected in higher non-tradable prices, eroding standards of living.

In spite of the relative complexity of the task ahead, one should keep in mind that the overall challenge remains modest - to find productive jobs for about 1 million Saudis over the next five years, in an economy whose GDP is close to $\$ 1$ trillion. What is needed is a three-prong strategy that tweaks the time-tested Saudization strategy further, by moving faster and more ambitiously on increasing the cost of expat labor, and that supplements labor policies with an industrial policy that helps domestic firms adapt faster to a new set of input prices, and by a conducive macro environment that makes room for the necessary investment needed to raise labor productivity. The rest of the chapter explores each of these themes in greater detail.

\section{The Central Challenge: Saudis Employability}

The key challenge then is to provide incentives for Saudi women and men to join the labor market in larger numbers, and for Saudi firms to hire them. 
As a background for this discussion, lets us summarize the well-known duality of the Saudi labor market. About 70 percent of nationals work for the public sector, while expatriates fill 80 percent of private sector jobs. About 4 million Saudis work for the public sector, and 1 million in the private sector.

According to data from the Central Authority for Statistics, the wage ratio between Saudi men that work in the public sector over that of those that work in the private sector is about 2 (Fig. 3.3). This means that Saudi current reservation wage is at around half the public sector wage. Unemployment benefits, close family ties and support, and the hope to get a wasta (connection) to join some part of the public sector will keep reservation wages from falling rapidly, even as the prospect of getting a public sector job fades away.

At the same time, a small proportion of Saudis already work in the private sector, where the men among them earn on average twice more than expats (and higher multiples for those with lower levels of education). Firms are thus willing to hire Saudis at wages above those of expats. This may reflect in part constraints on firms imposed by the Saudization program and, in parts, the comparative advantages of nationals in some sectors. But clearly, the demand by firms for national labor must be severely constrained by the size of the wage differentials.

Unemployment in such circumstances reflects both demand and supply constraints-Saudis with reservation wages too high given private sector

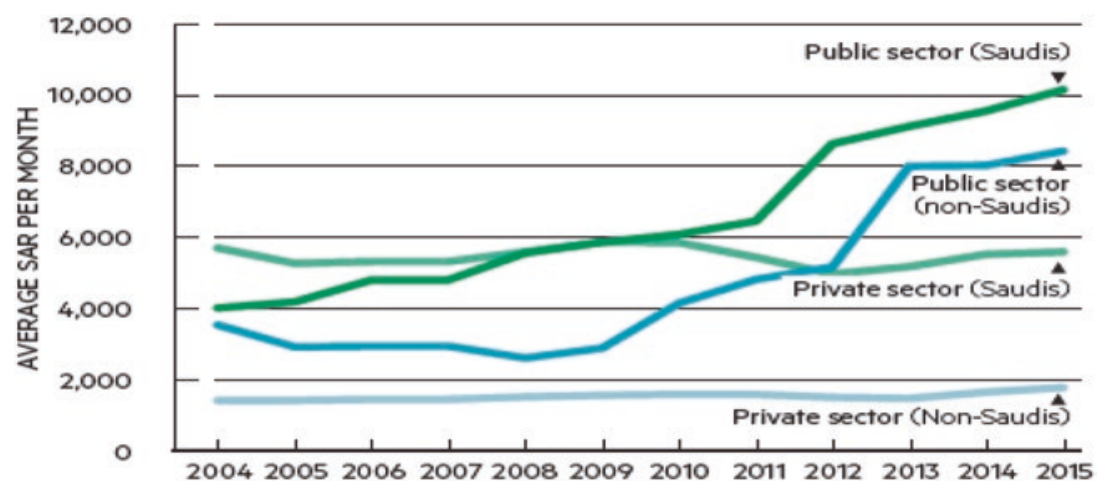

Fig. 3.3 Average month wages, 2004-2015. (Source: Ministry of Labor Report (2016)) 
wages for nationals, and firms finding it more profitable to hire cheaper expats. To improve the national labor force participation, expat wages need to go up in order to improve the attractiveness of national workers to firms, and/or national reservation wages need to go down to expand labor supply. The more movement in these prices, the faster Saudi employment would expand. The balance in the use of the two approaches will determine the terms of the burden sharing of reforming the labor market, that is, the welfare loss of workers versus that of firms. While cultural norms of low participation may initially create a resistance to the expansion of work, it is highly unlikely that these norms will not adjust to economic opportunities as they get created, as is the case around the world.

The labor market would therefore have to become much tighter, with constraints placed on the total number of migrants in the country-and not just firm-level quotas that are poorly applied, as is the case now. So far, the Saudization effort has largely focused on a system of quota for Saudi nationals in various sectors. But it has become clear over time that a system of growing quotas cannot work effectively unless the cost of employing expat rises at the same time, so that the (rising) quotas remain close to the quantity of national labor effectively demanded by the market. As long as it is cheaper to employ expats, rent-seeking would ensure that the quota system will leak. ${ }^{4}$ The current policy stance also includes efforts to shrink the Saudi-expat wage gap. The government-stated goal is to reduce it by 20 percent by 2022 . This goal seems however too modest. The main reason for the modest approach is that Saudization policies are naturally resisted by the corporate sector, since they lower profitability in the short term.

The alternative of squeezing the population into accepting lower reservation wages generates social discontent and resistance leading to delays and to policy reversals - so far, the government has backed down on several reforms that hurt the population (including wage cuts). Given the scale of the challenge, there is therefore a need to broaden the policy toolkit. There are three other ways to improve the labor force participation of Saudis in the non-oil sector besides taxing the expats and pushing Saudis to accept lower reservation wages: (1) to subsidize the private

\footnotetext{
${ }^{4}$ This will be exacerbated by the highly crony nature of the private sector, whose heights remain dominated by royals and families close to the court, and who had, until recently, a decisive influence over the application of policies and regulatory norms to their business concerns (Mazaheri 2016).
} 
sector wages of Saudis with a negative income tax; (2) to subsidize their in-firm training so as to improve their productivity; (3) to influence social norms and work condition in ways that encourage Saudi women to work more in the private sector. More likely, a successful strategy would use all these instruments.

The discussion above assumes that the challenge of creating jobs for Saudis is a problem of riches and that all that KSA needs to do is to substitute Saudi for foreign workers in existing positions. But simple substitution will not do. As stressed by various analysts, the 6 million jobs currently occupied by expats in the non-oil sector are either overly low skill or high skill intensive (Hertog 2014; Kabli 2014). This dualistic production structure has been molded by economic incentives-whenever possible, firms have tended to use production methods that take advantage of the low cost of unskilled labor, which saves on the necessity to invest in machinery and other productive assets. ${ }^{5}$ At the same time, the generous energy subsidies, and the large supply of loanable funds have also advantaged capital intensity among large firms, resulting overall in a two-peak aggregate production function, focused around the employment of low and high skills workers, to the detriment of technologies using middle levels of skills more intensely.

The problem with this two-peak dual production structure is that it does not correspond to the relative scarcity of national factors, as the Saudi labor force is now predominantly of a medium skill level (see Fig. 3.4). Thus, the type of needed structural change is one that upgrades laborintensive sectors, by adding capital, skills, and technology. On the positive side, such middle-skill jobs would be at higher productivity, allowing private firms to pay the higher wages needed to attract national labor without generating too much inflationary pressures. Such job upgrading should over time eliminate much of the menial positions occupied presently by expats.

The good news is that the education level among young Saudis has risen, which makes it possible for them to occupy jobs at relatively high productivity levels. The bad news, however, is that existing incentives have pushed firms in the private sector to create jobs that require either very low skills (especially in services) or very high skills (especially in the energy sector). To create jobs that are attractive for Saudis, who have mostly

\footnotetext{
${ }^{5}$ This is also reflected in a decline in aggregate labor productivity over the past decade, even as non-oil GDP rose fast.
} 


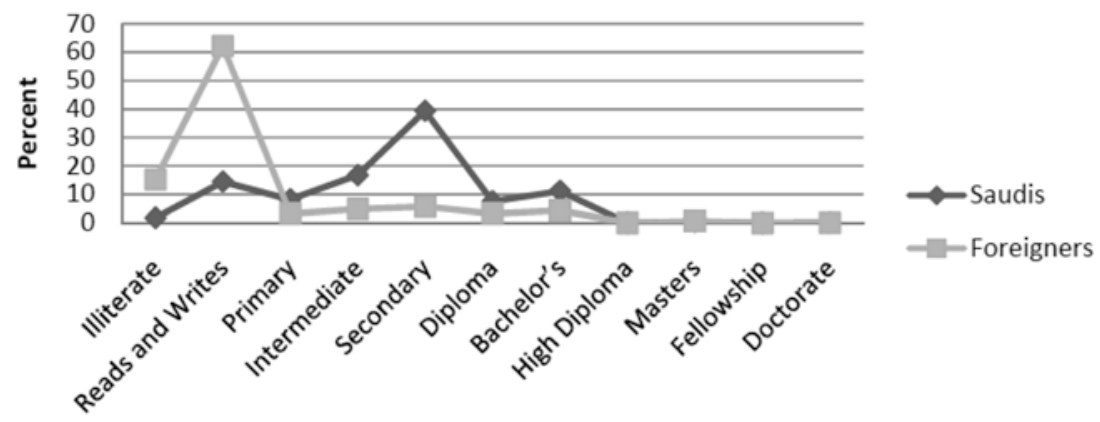

Fig. 3.4 Nationals and Expats employment in the non-oil sectors in relation to educational levels, 2010. (Source: Kabli 2014, using Ministry of Labor statistics)

mid-level skills, there is therefore a need for structural change in the production methods used by the private sector in response to changes in factor endowments and prices.

\section{The Policy Agenda Ahead}

There are two types of additional economic challenges to transitioning to a "normal" economy, besides the tightening up of the labor market (and a multitude of political-economic ones discussed in Sect. 6). These are related to the need: (1) to improve the dynamism of the private sector so as to support structural change; and (2) to make the right macroeconomic choices as related to speed in order to leave enough financial headroom for the financing of a technological upgrading of the private sector.

The first issue about the need for a more dynamic private sector is related to the need for structural change discussed above. The Vision 2030 document puts a lot of emphasis on the development of new small and medium-size enterprises (SMEs) to make the market economy more dynamic. According to national statistics, there are however more than 1.1 million firms with less than 50 employees, which is already a large figure. ${ }^{6}$ Indeed, a recent survey of SMEs by the General authority on Statistics reveals that an important constraint facing SMEs in KSA was too much competition and the implied lack of profitability (General Authority

\footnotetext{
${ }^{6}$ This can be compared to 1.5 million such firms in Turkey, a country with a population four times that of KSA.
} 
of Statistics 2017). What is needed then is not a net rise in the number of SMEs, but rather, the replacement of the old labor-intensive firms by new skill intensive ones.

Successful SMEs should afford to pay sufficient wages to attract Saudi workers by investing in more capital- and skill-intensive production methods, and by training their workers to improve their productivity. To encourage their entry will require however a much more ambitious effort to improve the business climate, which remains opaque and constraining, and to open up access to finance, which is now severely restricted for SMEs. These efforts will only help if, at the same time, the less efficient firms face higher labor costs and are pushed to close down and exit. Efforts should thus also be needed to facilitate the exit of firms that cease to be profitable, including a reform of the bankruptcy code. ${ }^{7}$

To help SMEs quickly adjust to the evolving input price structure (more expensive labor and other input costs), more targeted industrial policies would also be needed. The key challenge is to support the transformation of whole sectors-reforming the construction industry so that it can move from its current labor-intensive techniques to more capital- and skillintensive methods, or helping to create new SMEs that cater to a world where housework is three to four times more expensive, by creating substitute services in the transport, cleaning, child-care, and food sectors. In this transformation, individual firms face several externalities: (1) their (costly) discoveries will be imitated by others; (2) they may need to rely on inputs (say machinery) that are not yet produced (or serviced); and (3) they risk losing the workers that they train at great cost to their competitors. As with industrial policies more generally, the question is not as much whether such policies are needed, but rather how to implement them in ways that work. Success here would be judged by their ability to elicit innovation by the private sector, while avoiding rent-seeking (on this, see Rodrik 2009). It has been noted that Saudization is more achievable in sectors where the wage gap is smaller (Hertog 2014). In sectors with large wage gaps, a decision needs to be made about whether to sacrifice or rescue the sector. Construction and commerce are two sectors that would almost certainly need to be rescued given their important size (see Fig. 3.4). These sectors attract at present nearly 4 million uneducated expats and use labor-intensive methods to produce about 20 percent of

\footnotetext{
${ }^{7}$ Moreover, policies that help firms survive the coming hard times- such as support to compensate for higher energy costs-should carefully discriminate between firms that should, and those that should not survive.
} 
non-oil GDP (see Fig. 3.1). They need to be incentivized to increase their labor productivity by investing in machinery and technology.

In the absence of supporting policies, there is a risk of migrant jobs disappearing, but being replaced with only a limited number of jobs for nationals, as has been observed in the Saudization policies followed so far (Hertog 2014; Peck 2017). The recent work of Jennifer Peck (2017) on the effects of the Nitakat program between 2011 and 2012 illustrate well the risks of a half-baked strategy. Using a detailed dataset at the firm level, she finds that the new quotas imposed by the program managed over a period of 16 months to increase the number of Saudi jobs by 93,000. But, at the same time, the destructive effect of the program was considerable: 11,000 firms (mostly small ones) preferred to exit rather than have to respect the new quotas (or pay the fine); and 934,000 expat jobs were eliminated. These stark results owe much to the precipitous nature of the program-if firms were given more time, and had better access to finance, more of them might have adjusted in ways that would have rescued more jobs.

The second major set of policy issues is related to the broad macro framework and, specifically, to that of the speed of adjustment. As discussed earlier, the required new investments would generate large new financing needs. In order to pay sufficiently to attract Saudi workers and use their skills most productively, the new economy will need to invest in more capital- and skill-intensive production methods. These new financing needs are likely to be large. At the aggregate level, to create about one million jobs every 5 years, they can be of the order of $\$ 0.5$ trillion over the next ten years. These funds will have to come from the national banking and financial sectors, FDI, or from public funds. At the same time, overly capital-intensive firms and sectors, which rest on massive energy and capital subsidies, may need to be scaled down or eliminated, as financial capital becomes more scarce and in higher demand in medium-skill intensive sectors.

At the macro level, the need for large amount of investment finance creates a trade-off with the speed of adjustment. Large amounts of public financing of deficits would crowd out funds needed to finance privatesector investment. Given that the private investment required for a successful structural reform strategy is large, there is also a global finance trade-off. In the back-of-the-envelope calculations cited above, KSA's fiscal space can be evaluated at about $\$ 1$ Trillion. This makes it possible to wait 10 years to adjust, if nothing goes to investment. Alternatively, half of 
the space would be needed to create one million good new jobs. Thus, choices will have to be made. Slowing adjustment too much would constrain how much can be invested to upgrade jobs and productivity.

\section{The Political Economy Challenge}

Important elements of the reforms needed for KSA to become a "normal" economy are already in place. Vision 2030 focuses on many aspects of this agenda. Taxes are rising and subsidies are coming down slowly. Saudization policies, which were started a decade ago, are becoming more binding, and expats are becoming more expensive and are starting to leave in droves. And policy signals have been sent to encourage more innovative SMEs to enter domestic markets. But overall, the program projected by Vision 2030 is not sufficiently focused on the creation of jobs for nationals and is overly concerned with an unattainable diversification agenda. As such, it remains blurred and lacks credibility. To send an unmistakable signal that productive jobs are the priority, Saudization policies, and private sector development efforts, would need to become more ambitious. Mega-projects (such as Neon city) that could easily turn into white elephants should also be replaced by pragmatic industrial policies that help whole sub-sectors to upgrade rapidly.

In developing these policies, and beyond the important economic complexities discussed above, the deeper constraints to progress need to be found in the particular political economy of the Kingdom. It is only a bit of a caricature to state that the current growth model rests on a two separate deals: one deal with businesses for a free hand at importing labor from abroad, and one with citizens for guaranteed public sector jobs and lifelong support. With lower oil rents to share, the domestic settlement comes under strain. Cutting support for businessmen, the population, or both risks undermining the current national pact. The economic elites would oppose policies that lead to more restrictions on their ability to hire expats at low cost. They would claim that most Saudis' education and attitude are not favorable to their employment. National workers will resist a reduction in their reservation wage, claiming that it is the responsibility of the state to protect their consumption level.

To build support for reforms, the perception that the costs of reform are fairly shared by all groups will be essential. The main challenge for a successful transition to a "normal" economy is to avoid distributional 
fights. Often, reforms that have significant distributional implications end up pitting different groups against each other, with each trying to shift the burden of adjustment by engaging in a "war of attrition" in an attempt to wait the other group out (Alesina and Drazen 1991). This happens more when actors have low trust that costs and gains will be fairly shared among themselves.

Moreover, in order to reduce opposition to change, it does make sense for the state to try to smooth out the initial consumption drop by only lowering the fiscal deficit gradually, at the speed at which the private sector picks up steam in creating jobs for nationals.

On the political side, there are three main risks. First, a populist reform program that advantages labor over firms will have a hard time generating a supply response. The risk here is that expat jobs will be eliminated, but they would not be replaced by new Saudi jobs. But second, a program that puts firms ahead of labor will not manage to increase the size of the tax base, because as long as the current incentive system of firms does not change fundamentally, the creation of more jobs will only attract more migrants rather than employ more Saudis. There is thus a fine line to walk in order to ensure that the (largely front-loaded) burden and (mainly long-term) benefits of the reforms will be fairly balanced among the population. A failure to ensure such a balance brings in the third type of risk, which is that of ending up doing nothing, kicking the can down the road, and borrowing to avoid reform as long as possible. Such a path would only lead to slow decay, and the need for harsher adjustment down the road.

Finally, beyond economic plans that manage to reduce opposition to stabilization and reform by sharing the burden of reforms more fairly across groups and time, one cannot avoid wondering how politics will adjust in the long term to the demands of a more autonomous population and private sector. How the current political regime will choose to adjust the ways the country is governed once circumstances change remains highly uncertain. In the long term, rent distribution will become less dominant and it will become unable to neutralize political voice as much as it did in the past. KSA's truest exceptionalism-the richest non democratic large country in the world-will surely come under stress as incomes start shifting from a rentier logic, to one based on private initiative. 


\section{REFERENCES}

Alesina, Alberto, and Allan Drazen. "Why Are Stabilizations Delayed?" The American Economic Review 81.5 (1991): 1170-1188.

Cammett, Melani, Ishac Diwan, and Andrew Leber: Is Oil Good or Bad for Private Sector Development? Economic Research Forum, working paper, March 2019. Cairo, Egypt.

Coskun, Ali, Serhat Cevikel, and Vedat Akgiray. The role of the state in MENA capital markets. In Diwan, Malik, and Atiyas: Crony Capitalism in the Middle East. OUP, forthcoming, 2018.

General Authority of Statistics, Kingdom of Saudi Arabia: SME survey, 2017.

Espinoza, Raphael, Ghada Fayad, and Ananthakrishnan Prasad. The Macroeconomics of the Arab States of the Gulf. International Monetary Fund, 2013.

Hanieh, Adam. Capitalism and class in the Gulf Arab states. Springer, 2016.

Hertog, S. (2014). Arab Gulf States: An Assessment of Nationalization Policies. Gulf Labor Markets and Migration-GLMM. European University Institute \& Gulf Research Center.

International Monetary Fund. Article IV for Saudi Arabia, 2017, and 2018. Washington, DC.

Kabli, Saud. Unemployment in Saudi Arabia. AUC master's thesis, 2014.

Karl, Terry Lynn, The Paradox of Plenty, University of California Press, 1997.

Kingdom of Saudi Arabia. Vision 2030. Retrieved at: http://vision2030. gov.sa/en.

Mahroum, Sami. The Gulf States Expats Dividend. Project Syndicate, July 2016.

Mazaheri, Nimah. Oil Booms and Business Busts: Why Resource Wealth Hurts Entrepreneurs in the Developing World. Oxford University Press, 2016.

Ministry of labor and social development. Saudi Arabia Labor Market Report 2016. 3rd edition, Kingdom of Saudi Arabia, July 2016.

Peck, Jennifer R. "Can hiring quotas work? The effect of the Nitaqat program on the Saudi private sector." American Economic Journal: Economic Policy 9.2 (2017): 316-347.

Rodrik, Dani. "Industrial policy: don't ask why, ask how." Middle East Development Journal 1.01 (2009): 1-29. 
Open Access This chapter is licensed under the terms of the Creative Commons Attribution-NonCommercial-NoDerivatives 4.0 International License (http:// creativecommons.org/licenses/by-nc-nd/4.0/), which permits any noncommercial use, sharing, distribution and reproduction in any medium or format, as long as you give appropriate credit to the original author(s) and the source, provide a link to the Creative Commons license and indicate if you modified the licensed material. You do not have permission under this licence to share adapted material derived from this chapter or parts of it.

The images or other third party material in this chapter are included in the chapter's Creative Commons licence, unless indicated otherwise in a credit line to the material. If material is not included in the chapter's Creative Commons licence and your intended use is not permitted by statutory regulation or exceeds the permitted use, you will need to obtain permission directly from the copyright holder. 